\title{
Willingness of young men and women to be tested for Chlamydia trachomatis in three non-medical settings in Glasgow, UK
}

\author{
Karen Lorimer, Margaret E Reid, Graham J Hart
}

\begin{abstract}
Objective To assess the willingness of young men and women to be tested for Chlamydia trachomatis in three non-medical settings.

Methods Men and women aged between 16 and 24 years were invited to complete a self-administered questionnaire and provide a urine sample in non-medical settings: 'education' (one further education college), 'health and fitness' (three local authority leisure centres) and 'workplace' (two call centres).
\end{abstract}

Results Eighty-four percent of age-eligible users approached in the settings agreed to complete a questionnaire $(n=363)$. Among the sexually active people ( $n=346)$, the uptake of screening varied by setting [education $19.1 \%(22 / 115)$, health and fitness $48.8 \%$ (62/127), workplace $27.8 \%(29 / 104) ; p<0.001]$. Health and fitness settings (OR 4.08; $95 \% \mathrm{Cl} 2.04-8.14$ ) and perception of being at risk of having chlamydia (OR 2.47;
95\% Cl 1.33-4.58) were strong predictors of providing a urine sample. Adjusting for setting and age group $(<20$ years vs $20+$ years), women were less likely than men to provide a urine sample (OR $0.42 ; 95 \% \mathrm{Cl} 0.26-0.70)$. All five positive cases (4.4\%; $4.9 \%$ in men, $3.8 \%$ in women) were contacted with their results by a health adviser and invited to be treated at a local genitourinary medicine clinic.

Conclusions Men were more willing than women to be tested for $C$. trachomatis in these non-medical settings, but uptake varied by setting. Thus, increasing opportunities for the take-up of testing in particular nonmedical settings might be a more effective approach to including young men who are not reached by clinic control efforts.

Keywords chlamydia, non-medical, screening, sexually transmitted infections, STI

J Fam Plann Reprod Health Care 2009; 35(1): 21-26

(Accepted 18 June 2008)

\section{Introduction}

Chlamydia trachomatis is the most common bacterial sexually transmitted infection (STI) in the UK, and in Scotland there was an increase of $27 \%$ and $87 \%$, for female and male diagnoses, respectively, between 2002 and 2007. ${ }^{1}$ The highest incidence rates are among young people aged under 25 years. ${ }^{1}$ To date, chlamydia screening in the UK has largely been offered to women under 25 years attending clinical settings. Given that the majority of people with chlamydia infection will have no physical cue with which to seek health care, and few young people use specialist sexual health services, many people will not be reached by cliniccontrol efforts. Despite this, at the end of the first year of the National Chlamydia Screening Programme (NCSP) (England) only $5.4 \%$ of tests were conducted in non-clinical settings, such as school, further education and military settings. ${ }^{2}$ Postal testing kits have been made available in selected high street pharmacies (Boots) in England as part of a 2-year pilot ${ }^{3}$ and so England is witnessing an expansion in screening beyond traditional clinical sites to non-clinical venues. There is increasing interest in going 'beyond the clinic' if inroads are to be made to combating current levels of chlamydia infection in the population. More generally, non-clinical settings such as further education, ${ }^{4}$ health and

MRC Social and Public Health Sciences Unit, University of Glasgow, Glasgow, UK

Karen Lorimer, BA, PhD, Research Associate

University of Glasgow, Public Health and Health Policy, Glasgow, UK

Margaret E Reid, BA, PhD, Professor

Centre for Sexual Health \& HIV Research, University College London, London, UK

Graham J Hart, BA, PhD, Director

Correspondence to: Dr Karen Lorimer, MRC Social and Public Health Sciences Unit, University of Glasgow, 4 Lilybank Gardens, Glasgow G12 8RZ, UK. E-mail: karen@sphsu.mrc.ac.uk

\section{Key message points}

- In this study of Chlamydia trachomatis testing in three non-medical settings, willingness to provide a urine sample varied across the settings with health and fitness users most willing to provide a urine sample $(48 \%$, compared to $19 \%$ of education and $27 \%$ of workplace respondents).

- Men were more willing to submit to testing than women overall $(40.1 \%$ of all men providing a sample vs $26.8 \%$ of all women), with men in each setting more willing than women to participate.

- Improving access to screening may not be sufficient to increase uptake. Health promotion should build in potential setting and gender effects on willingness to provide a urine sample, during the planning stages.

fitness, ${ }^{5}$ workplace, ${ }^{6}$ military settings ${ }^{7}$ and youth detention ${ }^{8}$ have all been found feasible settings in which to offer screening. In addition, urine-based testing has been offered in population-based studies, such as part of British National Survey of Sexual Attitudes and Lifestyles (Natsal 2000)9,10 and as part of the Chlamydia Screening Studies (ClaSS) in Bristol. 11

In contrast with England, there is currently no national screening programme for chlamydia in Scotland, since health is a devolved matter. The Scottish Intercollegiate Guidelines Network (SIGN) (www.sign.ac.uk) recommend opportunistic screening for women under 25 years in clinical settings but with no screening recommended for men. ${ }^{12}$ Whilst offering screening in non-medical settings has been found to be feasible, the involvement of men has remained limited, both in Scotland and also in England. ${ }^{13-16}$ Clearly, methods for reaching asymptomatic 'hard-to-reach' persons, such as men, are required. Non-medical settings, such as educational, health and fitness, and workplace settings, could provide key access points to reach young people, but in particular young men. In this article we detail the willingness of men and women to be tested for chlamydia in three non-medical settings. We also describe the sexual 
behaviour of those who provided a sample for testing and those who declined, to assess the characteristics of persons willing to 'self refer'.

\section{Methods}

Chlamydia screening, by urine sample, was offered in three non-medical settings: 'education' (one further education college), 'health and fitness' (three local authority leisure centres) and 'workplace' (two call centres). In each setting, young people who appeared to be aged between 16 and 24 years were approached by one of the authors (KL) from a main area (canteen, main foyer or kitchen, respectively) of the settings, and invited to complete a self-administered questionnaire and to provide a urine sample to be tested for chlamydia, once their age was confirmed. Thus a convenience sample was used due to the way in which young people used the settings; purposive sampling would have lengthened the recruitment period in settings where young people used the canteen or kitchen intensively during lunch hours, or entered foyers sporadically, often in groups and at particular times, with lengthy gaps outwith or in between such times.

During initial contact, young people were informed about the nature of the study being one in which a selfadministered questionnaire would be completed and then, if they so chose, a urine sample could be given for chlamydia testing. Respondents were given two leaflets: one gave information about the study and the other information about chlamydia. These leaflets invited respondents to consider carefully the implications of participating in the study including, if they were to agree to testing, how they would feel if they were to receive a positive test result. Respondents were also given this information verbally by the researcher during this initial discussion (to ensure those who did/might not read the leaflets received the information). Young people were told they could complete a questionnaire and choose not to give a urine sample. Those willing to complete the questionnaire were asked to sign consent forms (which also asked for contact details) and then complete the questionnaire immediately, either at their table in the canteen or at a nearby seat in a quiet area of the main foyer, and return to the researcher. The last question on the back page of the questionnaire asked: 'Are you willing to give a urine sample today to be tested for chlamydia?' When questionnaires were returned the researcher checked their response and, where appropriate, confirmed willingness with respondents who ticked 'Yes' before proceeding with the testing process (including further discussion about the communication of their result, the method of contact and what would happen in the event of a positive result). Alternatively, a dialogue commenced with those who ticked 'No' (for example, asking if they had recently been tested) and also with those who responded 'Not sure'. Those not willing to provide a sample could remain in the study (for follow-up interviews).

Respondents who were willing to be tested were given a test kit (a standard $20 \mathrm{ml}$ container to collect urine, a clear plastic bag for their sample, and a white 'jiffy' bag). Collected specimens were labelled (study identifier, individual number, date, age and gender) and stored in a cool box container. Samples were couriered within 24 hours to a local testing laboratory and tested with the LCx probe system (Abbot Diagnostics, Maidenhead, UK). In the event of a positive test result, the researcher informed a local genitourinary medicine (GUM) clinic of the result (as stated on the consent form and as advised to respondents both before completing the questionnaire and before they gave a urine sample) and respondents were contacted by a health adviser from the GUM clinic and informed of their test result and subsequently managed according to the clinic's standard protocol. The researcher contacted those who received a negative result, via the method they chose on their consent forms (text message, telephone call to mobile or landline, letter or e-mail). Given the importance placed in the literature on obtaining accurate contact details from respondents when in the field, $5,17,18$ all respondents were asked on their consent form to provide two forms of contact; this information was checked and verified by the researcher with respondents who agreed to provide a urine sample.

A power calculation suggested that a sample size of 174 in each group (by gender) would detect a hypothesised difference in willingness to provide a urine sample. The power calculation assumed around $20 \%$ of respondents approached and completing a questionnaire would be willing to participate in screening; this was lower than the equivalent figure for postal screening ${ }^{19}$ due to a hypothesised influence of the public nature of the screening opportunity. Only the sexually active respondents (ie, 346/363) were included in analyses.

\section{Statistical analysis}

Statistical evaluation was performed with the Chi-square test and univariate and multiple logistic regression analysis using the Statistical Package for the Social Sciences (SPSS), version 14.0 (SPSS Inc., Chicago, IL, USA). The Fisher Exact test was used when greater than $25 \%$ of the expected cells were less than five. Statistical significance was at the $5 \%$ level.

\section{Ethical approval}

Ethical approval for this study was obtained from the University of Glasgow Faculty of Medicine Ethics Committee.

\section{Results}

Screening was offered in six settings between March 2004 and April 2005, within which 18 weeks and 230 hours of screening were conducted. Overall, 431 people (189 men and 242 women) attending the study sites were invited to complete the questionnaire and 363 participated $(84 \%$ of those approached): by setting, $86 \%(126 / 145)$ in the education setting, $84 \%(133 / 158)$ in health and fitness settings and $84 \%(104 / 128)$ in workplace settings. The mean age of respondents was 20 years.

\section{Willingness to provide a urine sample}

Uptake of screening was $32 \%$ overall (113/346). Health and fitness setting users were the most willing to provide a sample (48\%, compared to $19 \%$ of education and $27 \%$ of workplace respondents; $p<0.001)$. Although this study was not intended as a prevalence study (the sample was too small), the number of positive cases identified from screening is nevertheless useful to report: in total $5 / 113$ samples $(4.4 \%)$ were positive for $C$. trachomatis $(4.9 \%$ in men, $3.8 \%$ in women). All 113 respondents were contacted with their results (95\% chose text message); all five positive cases were successfully notified by the health adviser and subsequently became part of the standard referral to GUM process.

Determinants of willingness to provide a urine sample varied between the study settings (Table 1). In the education setting perception of risk was the only variable associated with willingness to provide a sample $(p=0.007)$; in health and fitness, gender $(p=0.010)$ and total number of lifetime sexual partners $(p=0.003)$ were determinants of willingness: more men provided a sample than women, as did those who reported higher numbers of lifetime sexual partners. Older age groups $(p=0.004)$ and those who 
Table 1 Determinants of willingness to provide a urine sample

\begin{tabular}{|c|c|c|c|}
\hline Determinant & $\begin{array}{l}\text { Participants (individuals } \\
\text { approached) }{ }^{\mathrm{a}}(n)\end{array}$ & $\begin{array}{l}\text { Individuals accepting } \\
\text { screening }[\mathrm{n},(\%)]\end{array}$ & $p$ value to $\chi^{2}$ test \\
\hline \multicolumn{4}{|c|}{ Education setting } \\
\hline & \multicolumn{3}{|c|}{ Sex } \\
\hline Female & $56(69)$ & $\begin{aligned} & 15(25) \\
& 7(12)\end{aligned}$ & 0.078 \\
\hline \multicolumn{4}{|c|}{ Age group (years) } \\
\hline $16-19$ & 59 & $10(17)$ & \multirow[t]{2}{*}{0.449} \\
\hline $20-24$ & 53 & $12(23)$ & \\
\hline \multicolumn{4}{|c|}{ Sexual partners in past 6 months $(n)$} \\
\hline $\begin{array}{l}\leq 1 \\
\geq 2\end{array}$ & 77 & $14(18)$ & \multirow[t]{2}{*}{0.708} \\
\hline \multicolumn{3}{|c|}{ Lifetime sexual partners $(n)$} & \\
\hline $1-2$ & 32 & $5(16)$ & \multirow[t]{4}{*}{$0.162^{c}$} \\
\hline $3-4$ & 28 & $3(11)$ & \\
\hline $5-9$ & 20 & $4(20)$ & \\
\hline $10+$ & 19 & 7 (37) & \\
\hline \multicolumn{4}{|c|}{ Prior experience of testing } \\
\hline Yes & 17 & $1(6)$ & \multirow[t]{2}{*}{$0.188^{c}$} \\
\hline No & 98 & $21(21)$ & \\
\hline \multicolumn{4}{|c|}{ Perceived themselves at risk } \\
\hline Yes & 59 & $17(29)$ & \multirow[t]{2}{*}{0.007} \\
\hline No & 56 & $5(9)$ & \\
\hline \multicolumn{4}{|c|}{ Health and fitness setting } \\
\hline Sex & & & \multirow{3}{*}{0.010} \\
\hline Male & $53(65)$ & $33(62)$ & \\
\hline Female & $74(93)$ & $29(40)$ & \\
\hline \multicolumn{4}{|c|}{ Age group (years) } \\
\hline $16-19$ & 33 & $9(27)$ & 0.004 \\
\hline $20-24$ & 94 & 53 (56) & \\
\hline Sexual partne & & & \\
\hline$\leq 1$ & 82 & $36(44)$ & 0.095 \\
\hline$\geq 2$ & 40 & $24(60)$ & \\
\hline Lifetime sexua & & & \\
\hline $1-2$ & 29 & $10(34)$ & $0.003^{c}$ \\
\hline $3-4$ & 31 & $11(35)$ & \\
\hline $5-9$ & 32 & $17(53)$ & \\
\hline $10+$ & 27 & $21(78)$ & \\
\hline Prior experien & & & \\
\hline Yes & 36 & $13(36)$ & 0.072 \\
\hline No & 91 & $49(54)$ & \\
\hline Perceived ther & & & \\
\hline Yes & 59 & $37(63)$ & 0.004 \\
\hline No & 68 & $25(37)$ & \\
\hline Workplace se & & & \\
\hline Sex & & & \\
\hline Male & $40(48)$ & $13(32)$ & 0.407 \\
\hline Female & $64(80)$ & $16(25)$ & \\
\hline Age group (ye & & & \\
\hline $16-19$ & 24 & $3(12)$ & 0.055 \\
\hline $20-24$ & 80 & $26(32)$ & \\
\hline Sexual partne & & & \\
\hline$\leq 1$ & 85 & $19(22)$ & 0.005 \\
\hline$\geq 2$ & 16 & $9(56)$ & \\
\hline Lifetime sexua & & & \\
\hline $1-2$ & 29 & $4(14)$ & $0.019^{c}$ \\
\hline $3-4$ & 19 & $5(26)$ & \\
\hline $5-9$ & 18 & $10(56)$ & \\
\hline $10+$ & 33 & $7(21)$ & \\
\hline Prior experien & & & \\
\hline Yes & 32 & 7 (22) & 0.362 \\
\hline No & 72 & $22(30)$ & \\
\hline Perceived the & & & \\
\hline Yes & 40 & $17(42)$ & 0.009 \\
\hline No & 64 & $12(19)$ & \\
\hline
\end{tabular}

aNumbers of men and women approached include sexually and non-sexually active; 363 people from 431 were willing to complete a questionnaire, of whom 346 were sexually active.

bThe 17 respondents who reported not being sexually active were excluded from analyses.

cFisher Exact test. Significant relationships between the variables and providing a urine sample are indicated by bold $p$ values.

perceived themselves at risk $(p=0.004)$ were also more willing to provide a sample in health and fitness settings. In workplace settings, increased perception of risk $(p=0.009)$ was also significantly associated with providing a urine sample. There was a trend for more older workplace respondents to provide a sample (those aged 20-24 years) than teenage respondents $(p=0.055)$; those who reported higher numbers of lifetime sexual partners were more likely to give a sample than those reporting fewer partners ( $p=$
$0.019)$, as did those who reported two or more sexual partners in the preceding 6 months $(p=0.005)$. In each of the study settings, respondents who perceived themselves to be at risk of having chlamydia were more willing to give a sample $(p<0.001)$.

Participation in testing varied by gender (with $40.1 \%$ of all men providing a sample vs $26.8 \%$ of all women; $p=$ $0.009)$, and in each setting men were more willing than women to give a sample, although this only reached 
Table 2 Effect of gender, setting and age on willingness to provide a urine sample, assessed by univariate (unadjusted) and multivariate (adjusted) logistic regression $(n=346)$

\begin{tabular}{lll}
\hline Determinant & $\begin{array}{l}\text { Unadjusted OR } \\
(95 \% \mathbf{C l})\end{array}$ & $\begin{array}{l}\text { Adjusted OR } \\
(95 \% \mathbf{C l})\end{array}$ \\
\hline Gender & $p=0.009$ & $p=0.001$ \\
Male & 1.00 & 1.00 \\
Female & $0.54(0.35-0.86)$ & $0.42(0.26-0.70)$ \\
Setting & $p<0.001$ & $p<0.001$ \\
Education & 1.00 & 1.00 \\
Health and fitness & $4.03(2.25-7.20)$ & $3.57(2.01-6.71)$ \\
Workplace & $1.63(0.86-3.07)$ & $1.34(0.74-2.81)$ \\
Age group (years) & $p<0.001$ & $p<0.001$ \\
16-19 & 1.00 & 1.00 \\
20-24 & $2.85(1.67-4.88)$ & $2.80(1.75-5.49)$ \\
\hline
\end{tabular}

$\mathrm{Cl}$, confidence interval; OR, odds ratio.

significance in health and fitness settings $(p=0.010)$ (Table 1)

The results shown in Table 2 demonstrate the odds ratio (OR) and $95 \%$ confidence interval (CI) of variables associated with willingness to provide a urine sample. Health and fitness and workplace settings were strong predictors of willingness to provide a urine sample. Thus, when adjusting for age and gender, setting still has an independent relationship with providing a urine sample.

Whilst in each setting respondents who perceived themselves to be at risk of having chlamydia were the most willing to provide a urine sample, multiple logistic regression analysis (which included sexual behaviour variables) found perception of risk to be the strongest predictor of willingness to provide a urine sample (OR 2.09; 95\% CI 1.19-3.67), with those who perceived themselves to be at risk or uncertain of their risk status more willing to provide a urine sample than those who reported they were not at risk.

\section{Characteristics of the respondents}

Multiple sex partners $(>1)$ in the preceding 6 months was reported more frequently by men than women $(39.2 \%$ vs $16.1 \% ; p<0.001)$. Men were more likely than women to report first intercourse before the age of 16 years $(43.7 \%$ vs $30.4 \% ; p=0.012$ ) and to have had more lifetime sexual partners $(p<0.001)$. No significant differences were found between respondents across the settings in terms of lifetime sexual partners and age at first intercourse; however, more health and fitness respondents compared with education and workplace reported two or more sexual partners in the preceding 6 months $(32.8 \%$, compared with $26.7 \%$ and $15.8 \%$, respectively; $p=0.026$ ).

Multiple logistic regression analysis was performed to assess which sexual behaviour variables (as detailed above) were the strongest predictors of willingness to provide a urine sample. Setting, age group and perception of being at risk of having chlamydia were the strongest predictors of providing a urine sample (Table 3 ).

\section{Prior experience of chlamydia testing or screening}

Overall, one in four $(24.9 \%)$ respondents reported they had previously been tested for chlamydia; however, $33.5 \%$ of women compared with $13.2 \%$ of men reported prior experience of testing $(p<0.001)$. Overall, $93.4 \%$ of all men who gave a sample reported no prior experience of chlamydia testing compared with $66.6 \%$ of women $(p<0.001)$. Reporting prior experience of chlamydia testing was significantly higher in workplace respondents compared with education and health and fitness respondents $(30.8 \%$, compared with $14.7 \%$ and $28.3 \%$, respectively; $p=0.004)$.
Table 3 Effect of gender, setting, age and sexual behaviour on willingness to provide a urine sample, assessed by univariate (unadjusted) and multivariate (adjusted) logistic regression ( $n=$ 346)

\begin{tabular}{|c|c|c|}
\hline Determinant & $\begin{array}{l}\text { Unadjusted OR } \\
(95 \% \mathrm{Cl})\end{array}$ & $\begin{array}{l}\text { Adjusted OR } \\
(95 \% \mathrm{Cl})\end{array}$ \\
\hline Gender & $p=0.009$ & $p=0.080$ \\
\hline Male & 1.00 & 1.00 \\
\hline Female & $0.54(0.35-0.86)$ & $0.59(0.32-1.06)$ \\
\hline Setting & $p<0.001$ & $p<0.001$ \\
\hline Education & 1.00 & 1.00 \\
\hline Health and fitness & $4.03(2.25-7.20)$ & $4.08(2.04-8.14)$ \\
\hline Workplace & $1.63(0.86-3.07)$ & $1.38(0.65-2.91)$ \\
\hline Age group (years) & $p<0.001$ & $p<0.001$ \\
\hline $16-19$ & 1.00 & 1.00 \\
\hline $20-24$ & $2.85(1.67-4.88)$ & $3.55(1.78-7.07)$ \\
\hline Age at first sex (years) & $p=0.946$ & $p=0.598$ \\
\hline$>16$ & 1.00 & 1.00 \\
\hline$\geq 16$ & $1.01(0.63-1.63)$ & $1.17(0.64-2.14)$ \\
\hline Condom used at & $p=0.065$ & $p=0.979$ \\
\hline first sex & & \\
\hline No & 1.00 & 1.00 \\
\hline Yes & $0.63(0.38-1.03)$ & $0.99(0.54-1.83)$ \\
\hline Lifetime sexual & $p=0.004$ & $p=0.955$ \\
\hline partners $(n)$ & & \\
\hline$<10$ & 1.00 & 1.00 \\
\hline$\geq 10$ & $1.94(1.15-3.29)$ & $1.02(0.50-2.07)$ \\
\hline Sexual partners in & $p=0.001$ & $p=0.206$ \\
\hline the past 6 months $(n)$ & & \\
\hline $\begin{array}{l}<2 \\
\geq 2\end{array}$ & $\begin{array}{l}1.00 \\
219(131-366)\end{array}$ & $\begin{array}{l}1.00 \\
1.55(0.78-3.07)\end{array}$ \\
\hline Ever been tested for & $2.19(1.31-3.66)$ & \\
\hline chlamydia & $p=0.141$ & $p=0.112$ \\
\hline No & 1.00 & 1.00 \\
\hline Yes & $0.60(0.35-1.05)$ & $0.57(0.29-1.14)$ \\
\hline $\begin{array}{l}\text { Perceive self to be } \\
\text { at risk }\end{array}$ & $p<0.001$ & $p<0.001$ \\
\hline No & 1.00 & 1.00 \\
\hline Yes & $2.83(1.78-4.51)$ & $2.47(1.33-4.58)$ \\
\hline
\end{tabular}

$\mathrm{Cl}$, confidence interval; OR, odds ratio.

However, prior experience of testing was not associated with willingness to provide a sample for testing in any of the study settings (Table 1).

\section{Discussion}

This non-medical approach to chlamydia testing was successful in engaging men and women in testing in six settings (one education, three health and fitness and two workplace settings). One-third of all young people were willing to provide a sample of urine for testing. The uptake of testing in these settings is similar to previous non-medical studies, such as a $38.5 \%$ uptake via Internet postal testing among men aged 22 years 20 and $31.5 \%$ via postal testing. 19 The higher uptake rate of $60 \%$ reported in one study with young men recruited in a university sports arena ${ }^{5}$ could be attributed to the fact that the young men were asked for a urine sample for reasons not related to chlamydia testing and were only subsequently asked for permission to carry out the additional test. We obtained the same rate in the health and fitness settings among the male respondents with the urine sample being collected solely for chlamydia testing. The higher percentage of tests obtained from health and fitness users, compared to education and workplace, suggests there was variability in uptake in testing across the three nonmedical settings. Given the attempts to implement a consistent offer of testing in each of the settings, this variability suggests there exists a complexity of motivators to willingness to accept testing in non-medical settings. Other work which has involved multiple settings have also reported variability in uptake across settings. $18,21,22$

Whilst uptake of testing can suggest acceptability and willingness, nevertheless the utility of a non-medical 
approach to testing lies in its potential to identify infections, and reaching populations that would not otherwise receive screening opportunities. Given the recommendations of the SIGN guidelines in Scotland and the NCSP in England, women already have other venues in which they are more likely to be offered screening or testing (e.g. family planning and general practice settings), and indeed a greater proportion of the women in the sample $(33.5 \%)$ had already been screened/tested for chlamydia than the men (13.2\%). This might explain why a greater proportion of men were willing to provide a sample compared with the women, particularly in the health and fitness setting, where despite more women than men completing a questionnaire men were much more willing to accept testing. Thus, although the involvement of women in this study suggests that some will find non-medical settings acceptable, it may be that men, who have fewer other options beyond GUM settings to be tested, may benefit more from a non-medical approach to testing.

This study has demonstrated that men do not necessarily hold avoidant attitudes towards their sexual health. It may be that young men seek a service that is easier to access and more convenient for them; non-medical settings could be one way of tailoring testing or screening to meet such needs. Continuing to investigate how best to reach young men and reducing the reservoir of infection that exists among young men is crucial if we are to offer primary prevention for women. By continuing with attempts to bring men into the screening and testing process then the current inequalities that exist in chlamydia screening could also be tackled.

Some limitations of the study should be considered. A time of 230 hours was taken to recruit 363 young men and women into the study. The amount of time it took to attract the sample is not replicable in routine health service delivery, and thus the strictly research focus of the study needs to be acknowledged. The use of convenience sampling meant that respondents were not chosen randomly and selection bias may have occurred. In addition, recall and social desirability biases may have occurred in responses to questionnaire items. Only respondents who used the study settings were approached and invited to participate in screening. It stands to reason that young people with higher-risk sexual behaviour, and those who do not regularly attend education, health and fitness and workplace settings, will not be reached by such an approach to screening. However, such an approach may prove useful if used in conjunction with other innovative methods to reach young at-risk people as well as clinic-based testing. Postal testing kits available in high street stores, for example, have proven popular with young men, with $80 \%$ of male tests coming from postal testing kits in one study. ${ }^{13}$ Issues of coverage do remain a problem with such an approach and thus it is important to continue to explore how best to reach high-risk groups. Despite these methodological limitations, this study was able to obtain sexual behaviour data for both men and women who gave a urine sample and those who did not when offered in nonmedical settings.

The success of the approach used in this study in reaching young men is in keeping with the findings from Healthy Respect, which had greater success in reaching young men through the innovative postal testing kits than women. ${ }^{13}$ Sternberg and Hubley (2004) conducted a metaanalysis of evaluations of interventions that have targeted heterosexual men and found a common theme among the literature was the interventions' ability to reach young men. ${ }^{23}$ Strategies found to be effective include: peer education programmes, large-scale media campaigns, workplace health programmes and non-medical outreach. The authors noted that merely providing services might not be enough to encourage their use by heterosexual young men. This view contrasts with others who advocate 'targeting men with equal emphasis' to women. ${ }^{21}$ The findings of this study - that men may be better reached through this 'innovative' approach to testing and that there is therefore a gendered response to the offer of chlamydia testing - suggests social factors are important in the delivery of services. Opportunities for screening and testing that reflect the social and cultural backdrop may prove more effective in the longer term, rather than a 'one-size-fits-all' approach. The effects of context, impact of gender and selfefficacy require further investigation to strengthen our understanding of how effective non-medical approaches to screening can be as part of control strategies to reduce the prevalence of chlamydia infection. However, as commentators are increasingly advocating, 2,24,25 all of this should be directed by the pressing need to involve young men in chlamydia screening.

\section{Acknowledgements}

The authors are grateful to Mr Harper Gilmour, University of Glasgow, Public Health and Health Policy, and Mr Geoff Der, MRC Social and Public Health Sciences Unit for advice on statistical analysis; laboratory staff at the West of Scotland Regional Virus Laboratory; health advisers at the Sandyford Initiative, Glasgow for management of positive cases; and Durex ${ }^{\mathrm{TM}}$ for providing condoms to distribute to participants.

Statements on funding and competing interests

Funding This study was funded by the Chief Scientist Office (Scottish Government) (Grant No. CZS/1/25).

Competing interests None identified.

\section{References}

1 Health Protection Scotland. Genital Herpes Simplex, Genital Chlamydia and Gonorrhoea Infection in Scotland: Laboratory Diagnoses 1998-2007, (Vol. 42, No. 12). Glasgow, UK: Health Protection Scotland, 2008.

2 LaMontagne DS, Fenton K, Randall S, Anderson S, Carter P. Establishing the National Chlamydia Screening Programme in England: results from the first full year of screening. Sex Transm Infect 2004; 80: 335-341.

3 Taylor Nelson Sofres plc. Chlamydia Screening Evaluation Interim Report - Wave One. Report prepared by TNS for The Department of Health (125331, November 2005-April 2006). 2007. http://www.dh.gov.uk/assetRoot/04/13/99/84/04139984. pdf [Accessed 6 April 2008]

4 Low N, Connell P, McKevitt C, Baggili T, Tenant-Flowers M, More C, et al. 'You can't tell by looking': pilot study of a communitybased intervention to detect asymptomatic sexually transmitted infections. Int J STD AIDS 2003; 14: 830-834.

5 Powell J, O'Conner C, O'Hiarlaithe M, Saunders J, de Freitas J. Chlamydia trachomatis prevalence in men in the mid-west of Ireland. Sex Transm Infect 2005; 80: 349-353.

6 The Men's Health Forum. Men and Chlamydia Project Final Report. London, UK: The Men's Health Forum, 2005.

7 McKay L, Clery H, Carrick-Anderson K, Hollis S, Scott G. Genital Chlamydia trachomatis infection in a subgroup of young men in the UK. Lancet 2003; 361: 1792.

8 David N, Tang A. Sexually transmitted infections in a young offenders institution in the UK. Int J STD AIDS 2003; 14: 511-513.

9 Fenton KA, Korovessis C, Johnson AM, McCadden A, McManus $\mathrm{S}$, Wellings $\mathrm{K}$, et al. Sexual behaviour in Britain: reported sexually transmitted infections and prevalent genital Chlamydia trachomatis infection. Lancet 2001; 358: 1851-1854.

10 McCadden A, Fenton K, McManus S, Mercer CH, Erens B, Carder C, et al. Chlamydia trachomatis testing in the Second British Survey of Sexual Attitudes and Lifestyles: respondent uptake and treatment outcomes. Sex Transm Dis 2005; 32: 387-394.

11 Low N, McCarthy A, Macleod J, Salisbury C, Horner PJ, Roberts $\mathrm{TE}$, et al. The chlamydia screening studies: rationale and design. Sex Transm Infect 2004; 80: 342-348.

12 Scottish Intercollegiate Guidelines Network (SIGN). Management of Genital Chlamydia trachomatis Infection. Edinburgh, UK: SIGN Secretariat, Royal College of Physicians, 2000.

13 Williamson LM, Scott G, Carrick-Anderson K, Kernaghan K, Hart GJ. Chlamydia trachomatis testing among 13-25-year-olds in 
non-genitourinary medicine settings. J Fam Plann Reprod Health Care 2007; 33: 177-182.

14 National Chlamydia Screening Steering Group (NCSSG). First Steps: Annual Report of the National Chlamydia Screening Programme in England, 2003/2004. London, UK: Department of Health, 2004.

15 National Chlamydia Screening Steering Group (NCSSG). Looking Back, Moving Forward: Annual Report for the National Chlamydia Screening Programme in England, 2004/05. London, UK: Department of Health, 2005.

16 National Chlamydia Screening Steering Group (NCSSG). New Frontiers: Annual Report of the National Chlamydia Screening Programme in England 2005/2006. London, UK: Health Protection Agency, 2006.

17 Jones K, Webb A, Mallinson H, Birley H. Outreach health adviser in a community clinic screening programme improves management of genital chlamydia infection. Sex Transm Infect 2002; 78: 101-105.

18 Poulin C, Alary M, Bernier F, Carbonneau D, Boily M, Joly JR. Prevalence of Chlamydia trachomatis and Neisseria gonorrhoeae among at-risk women, young sex workers, and street youth attending community organizations in Quebec City, Canada. Sex Transm Dis 2001; 28: 437-443.

19 Macleod J, Holloway A, Morcom A, Hobbs FDR, Salisbury C,
Patel R, et al. Coverage and uptake of systematic postal screening for genital Chlamydia trachomatis and prevalence of infection in the United Kingdom general population: cross sectional study. BMJ 2005; 330: 940-942.

20 Novak DP, Edman AC, Jonsson M, Karlson RB. The internet, a simple and convenient tool in Chlamydia trachomatis screening of young people. Euro Surveill 2003; 8: 171-176.

21 Sripada S, Logan S, McGillivray S, Mckenzie H, Templeton A, Hamilton $\mathrm{M}$, et al. Opportunistic screening for Chlamydia trachomatis in men attending three different secondary health care settings. Sex Transm Infect 2007; 83: 282-285.

22 Jones CA, Knaup RC, Hayes M, Stoner BP. Urine screening for gonococcal and chlamydial infections at community-based organizations in a high-morbidity area. Sex Transm Dis 2000; 27: 146-151.

23 Sternberg P, Hubley J. Evaluating men's involvement as a strategy in sexual and reproductive health promotion. Health Promot Int 2004; 19: 389-396.

24 Fenton KA. Screening men for Chlamydia trachomatis infection: have we explored the possibilities? Commun Dis Public Health 2000; 3: 86-89.

25 Hart G, Duncan B, Fenton KA. Chlamydia screening and sexual health. Sex Transm Infect 2002; 78: 396-397.

\section{Testing and quantifying association in binary data}

\section{Pamela Warner}

\section{Background}

Both Chi-square test and logistic regression have been used to explore association in an article in this issue of the Journal. ${ }^{1}$ These notes are intended to provide readers with some supplementary explanation and comparison of these statistical methods. [See Box 1 for glossary of terms.]

\section{What is it?}

The Chi-square test can be used to test the null hypothesis $(\mathrm{NH})$ of 'no association' between two categorical variables. When both outcome variable and explanatory variable are binary, there are only four possible combinations of values for outcome/explanatory variable, and hence study sample data can be accumulated in a classic $2 \times 2$ table of frequency counts. [NB. Chi-square tests can be undertaken for larger tables, but these notes consider only $2 \times 2$ tables.] For binary data, the research question of interest is typically: "Is there an association between outcome (screening uptake) and an explanatory factor (gender)?", for example, "Does uptake differ between males and females?". That is, the test is equivalent to testing the $\mathrm{NH}$ of no difference in proportions (or percentages) of individuals with the outcome.

\section{When and why is it useful?}

The Chi-square test is extremely useful in most $2 \times 2$ tables for testing association. It examines the observed cell counts (the data from the study sample), and compares these to cell

\section{J Fam Plann Reprod Health Care 2009; 35(1): 26-27}

Public Health Sciences, University of Edinburgh Medical School, Edinburgh, UK

Pamela Warner, BSc, PhD, Senior Lecturer in Medical Statistics and Associate Editor, Journal of Family Planning and Reproductive Health Care

Correspondence to: Dr Pamela Warner, Public Health Sciences, University of Edinburgh Medical School, Teviot Place, Edinburgh EH8 9AG, UK. E-mail: p.warner@ed.ac.uk counts that would be expected if there were truly no association between the two variables. The Chi-square value calculated from the sample data is referred to tables of the Chi-square distribution, to ascertain the significance probability (under the $\mathrm{NH}$ ). If this probability is sufficiently low (conventionally $<5 \%$ or $<1 \%$ ) then the data are judged too unlikely for the $\mathrm{NH}$ to be true, so we conclude, by reverse logic, that the $\mathrm{NH}$ must be false, that there is therefore an association.

\section{What precautions are needed?}

The validity of the Chi-square test for $2 \times 2$ tables is good if the total $n$ is greater than 40 . If the total $n$ is between 20 and 40 then validity remains good provided none of the four expected cell counts is less than 5. Otherwise, or if total $n$ is less than 20, Fisher Exact test should be used instead of Chisquare. ${ }^{2}$

The Chi-square test does not provide a measure of the degree of association. The significance probability cannot serve this purpose, since it reflects the overall $n$ as well as the degree of association. Therefore in reporting Chi-square results it is recommended to present, in addition to the numbers and percentages with the outcome in both explanatory variable subgroups, a summary statistic estimating the association, preferably with a confidence interval for the estimate. Possibilities for the summary are the difference in proportions/percentages or, alternatively, a ratio summary statistic [e.g. odds ratio (OR)].

\section{Example of techniques}

Table 1 shows the results when applying (to the data reported by Lorimer et al. in Table $1^{1}$ ) the Chi-square test of association of screening uptake and sex, both separately by setting and overall (ignoring setting). Across settings (which are fairly similar in size, $n=104$ to 127 ), the more extreme the sex difference in uptake percentage, the larger is the Chisquare value, and smaller (more significant) the $p$ value. The difference overall is similar to that for the education setting (about 13 percentage points), but the much larger overall $n$ 